\title{
The Role of Trait and State Perfectionism in Psychological Detachment From Daily Job Demands
}

\section{Dorota Reis $^{1}$ (1) | Elisabeth Prestele ${ }^{2}$}

\author{
${ }^{1}$ Saarland University, Saarbrücken, Germany \\ ${ }^{2}$ University of Koblenz-Landau, Landau

\section{Correspondence} \\ Dorota Reis, Saarland University, Campus A2 \\ 4, 66123 Saarbrücken, Germany. \\ Email: dorota.reis@uni-saarland.de \\ Funding information \\ Research Fund, Saarland University
}

\begin{abstract}
Psychological detachment has been proposed to be a mediator of the relations between an individual's responses to stressful work-related experiences and midand long-term health. However, the number of studies that have specifically examined the role that personal characteristics play in these associations is considerably small. One personal characteristic that might specifically interfere with psychological detachment is perfectionism, which has been considered an important vulnerability factor for the development of psychological disorders. Hence, the goal of this registered report was to extend research on psychological detachment by introducing trait and state perfectionism as moderators of the aforementioned relations. We conducted an experience sampling study with three measurement occasions per day over the course of 3 working weeks ( $N=158$ employees; $M_{\text {age }}=41.6 ; 67 \%$ women). Multilevel path models showed that perfectionistic concerns consistently determined strain responses at between- and within-levels of analyses even after the effects of job demands (i.e., unfinished tasks and role ambiguity) and detachment were accounted for. However, we found no evidence for the proposed moderation effects. The theoretical implications for the understanding of the processes proposed in the stressor-detachment model are discussed.
\end{abstract}

\section{KEYWORDS}

job stress, multilevel moderated mediation model, perfectionism, psychological detachment, registered report

\section{1 | INTRODUCTION}

Because work-related stress has become even more prevalent over the last few years (OECD, 2012), research in occupational health psychology has aimed to identify protective individual and organizational factors that might buffer its impact. One of these individual factors is an employee's ability to recover from work. This concept captures the mechanisms that counterbalance employees' reactions to job demands and thus help employees maintain work-related well-being and health (Sonnentag \& Fritz, 2015). In this vein, in recent years, recovery from work has gained increased attention (e.g., Demerouti, Bakker, Geurts, \& Taris, 2009; Geurts \& Sonnentag, 2006; Sonnentag, Venz, \& Casper, 2017).

The recently proposed stressor-detachment model (SD model; Sonnentag, 2011; Sonnentag \& Fritz, 2015) offers a coherent framework by which to systematize existing studies and to guide future research on recovery and its associations with job stressors and strain-at both micro (i.e., within days) and macro levels (i.e., longitudinally). In this model, psychological detachment is defined as the core concept of recovery, and it "means refraining from job- 
related activities and mentally disengaging from work during time off the job" (Sonnentag \& Fritz, 2015, p. 72). Thus, psychological detachment encompasses the absence of perseverative thinking about work (i.e., work-related rumination or worry), the absence of nonrepetitive thinking about work (i.e., problem-solving thinking or positive work reflection), and not being involved in any work-related tasks. In the model, job stressors refer to a broad category of aspects of a job that can lead to acute and chronic strain reactions such as physical or psychological impairments or feelings of cognitive and emotional exhaustion. Psychological detachment mediates the relation between job demands and strain, which implies that although better detachment is related to less acute and chronic strain reactions (Geurts \& Sonnentag, 2006), high levels of job stressors may impede detachment from work. This is critical because employees who face more intense job stressors are especially in need of detaching from work.

The SD model can promote research on recovery owing to its conceptual clarity in focusing on psychological detachment as the prototypical recovery experience, the possibility of examining different types of stressors (e.g., unfinished tasks and role ambiguity) and strains (e.g., sleep quality and fatigue, see Sonnentag \& Fritz, 2015) in the model and their respective relations to psychological detachment, and its consideration of short- and long-term associations between the constructs that are involved. However, the number of studies that have specifically examined the role of personal characteristics in the SD model is considerably small. This is quite surprising given that it is likely that individual differences in people's responses to job demands exist and should consequently serve as moderators of the micro- and macrolevel processes proposed in the SD model.

One personal characteristic that might specifically interfere with psychological detachment is perfectionism. Perfectionism has been considered an important vulnerability factor for the development of psychological disorders in general (see Egan, Wade, \& Shafran, 2011; Egan, Wade, \& Shafran, 2012, for reviews). In particular, perfectionism has been both theoretically and empirically shown to be an important predictor of variables that are central parts of the SD model (psychological detachment and strain) and to act as a moderator of responses to stressors. Derived from this prior evidence, we propose that both trait perfectionism (macro-level) and state perfectionistic cognitions (micro-level) should affect how individuals respond to specific job demands, and as a consequence, how successful they will be at detaching from these demands and at reducing strain. In short, we predict that high levels of state and trait perfectionism will pose an additional barrier to scaling down strain responses directly and indirectly by posing an additional barrier to the ability to mentally disconnect from work.

We are pursuing several goals with this research. Most important, we aim to extend research on the SD model by introducing trait and state perfectionism as moderators of the relations in the model. From a between-persons perspective, we propose that trait perfectionism will moderate how general levels of job demands are related to general levels of both psychological detachment and strain. Moreover, we aim to explore the role of perfectionism from a within-persons perspective. That is, we propose that an employee's perfectionistic cognitions, which fluctuate from day to day, have thus far been neglected but are likely to be important predictors of daily psychological detachment and daily strain. With this approach, we aim to improve insights into the direct and mediation processes proposed in the SD model. A better understanding of the underlying mechanisms seems critical: Given that employees are limited in the extent to which they can modify the characteristics of their jobs, the ways in which they deal with job stressors in order to detach may provide a starting point for interventions.

\section{1 | TRAIT PERFECTIONISM AND PERFECTIONISTIC COGNITIONS}

Perfectionism has been described as a clinical personality trait that has been associated with the development and maintenance of a variety of psychological disorders (depression, posttraumatic stress disorder, burnout, anxiety, obsessive-compulsive disorder, and somatoform disorders; see Egan, Wade, \& Shafran, 2011, 2012, for reviews). Thereby, the diverse facets of perfectionism can be summarized by two dimensions (see Stoeber \& Gaudreau, 2017, for a recent review). The first is a critical evaluation of one's own behavior and concerns about the consequences of not living up to one's standards (Dispositional Perfectionistic Concerns; DPC). This dimension has consistently been linked with psychological maladjustment. The second is the setting of and striving for extremely high standards (Dispositional Perfectionistic Strivings; DPS). This second dimension has shown more positive associations with psychological adjustment, especially when the overlap with DPC was controlled for (see Hill, Huelsman, \& Araujo, 2010; Stoeber \& Gaudreau, 2017, for overviews). Beyond these main effects of trait perfectionism on psychological adjustment, the diathesis-stress model states that certain facets of perfectionism should enhance the probability that distress will emerge in the face of a stressful situation (Chang \& Rand, 2000; Flett, Hewitt, \& Dyck, 1989; Hewitt \& Dyck, 1986). Different studies have supported the idea that DPC were associated with an enhanced reactivity to daily stress, life stress, and experimentally induced demands, whereas DPS were associated with less negative and even some positive responses, especially when the overlap with DPC was controlled for (e.g., Besser, Flett, Hewitt, \& Guez, 2008; Chang \& Rand, 2000; Mandel, Dunkley, \& Moroz, 2015; Wirtz et al., 2007). Whereas perfectionism has frequently been investigated in student and athlete samples, the specific role of perfectionism for employees' job-related behavior and wellbeing has been left largely unexplored. Initial results have indicated that DPC might also have detrimental effects on job-related variables such as burnout, work engagement, or workaholism in employees (see Stoeber \& Damian, 2016, for an overview). As such, it might be a valuable extension of existing research to investigate DPS and DPC as person-specific vulnerability factors for responses to job stressors in the SD model framework.

In order to advance the understanding of whether, under what conditions, and how the dimensions of perfectionism are associated 
with job-related strain, it is vital to understand how these distal variables are associated with cognitive and affective responses to specific stressors. It is assumed that DPS and DPC affect the cognitive processing of given situations. Empirical results have indicated that situations that are objectively not very demanding can become significant stressors in the subjective perception of a perfectionist because such situations can initiate dysfunctional cognitive processes such as dysfunctional appraisals, negative automatic thoughts, or rumination (Cox \& Chen, 2015; Flaxman et al., 2017; Flett, Newby, Hewitt, \& Persaud, 2011; Zureck, Altstötter-Gleich, Gerstenberg, \& Schmitt, 2015). Specifically, perfectionistic cognitions have been defined as state-like manifestations of perfectionism in the form of specific automatic and ruminative thoughts that should emerge when the perfectionistic self-schema is activated by situational cues (e.g., demanding situations that indicate opportunities for perfection or imperfection; Flett, Hewitt, Blankstein, \& Gray, 1998; Stoeber, Kobori, \& Tanno, 2010). Thus, the frequency of perfectionistic cognitions should vary within persons as a function of demands, triggering the translation of cognitive schemas into perfectionistic cognitions (see Flett et al., 2012; Flett, Hewitt, Blankstein, \& Gray, 1998; Flett, Hewitt, Whelan, \& Martin, 2007).

On the other hand, the frequency with which perfectionistic cognitions occur should vary between persons due to betweenperson differences in the underlying cognitive schemas represented by the dimensions of dispositional perfectionism and their facets. Like the more general constructs of automatic thoughts and rumination, perfectionistic cognitions are thought to be frequently activated and repetitive (e.g., Flett, Hewitt, Blankstein, \& Gray, 1998). However, the specific content of perfectionistic cognitions has been conceptualized as a more direct translation of a perfectionistic self-schema in the form of current thoughts concerning the high personal relevance of striving for one's high standards and of avoiding even minor shortfalls than more general negative automatic or ruminative thoughts might be. Empirically, measures of perfectionistic cognitions have been found to be associated with positive and negative automatic thoughts and a ruminative response style, but they have still been found to add incremental validity in predicting psychological distress beyond these variables (Flett, Hewitt, Blankstein, \& Gray, 1998; Flett, Madorsky, Hewitt, \& Heisel, 2002). Prior cross-sectional studies have found that individuals with more frequent perfectionistic cognitions generally experience higher levels of distress (e.g., Flett et al., 2012; Flett, Hewitt, Blankstein, \& Gray, 1998; Stoeber, Kobori, \& Brown, 2014) and, in particular, tend to experience enhanced and prolonged reactivity to stressors (Flett, Nepon, Hewitt, \& Fitzgerald, 2016).

As has frequently been shown on the level of dispositional perfectionism, it has been valuable to differentiate between cognitions that mirror thoughts about having high standards for oneself (Perfectionistic Strivings Cognitions; PSC) and thoughts about mistakes and their negative consequences (Perfectionistic Concerns Cognitions; PCC) because the two have demonstrated differential associations with psychological adjustment (Kobori \& Tanno, 2005; Prestele \& Altstötter-Gleich, 2018; Stoeber, Kobori, \& Brown,
2014; Stoeber, Kobori, \& Tanno, 2010). Whereas PCC have consistently shown positive associations with different indicators of distress, PSC have been found to be mostly unrelated or even negatively related to distress. To the best of our knowledge, only two studies have investigated variations in perfectionistic cognitions from day to day (Prestele \& Altstötter-Gleich, 2018; Prestele, Altstötter-Gleich, \& Lischetzke, 2019). However, the conceptualization of perfectionistic cognitions as representing the cognitive state of perfectionism in the form of current thoughts that might vary within persons represents a valuable way to supplement the investigation of between-person differences in trait perfectionism.

In this vein, we propose that both the differentiation between dispositional perfectionism and perfectionistic cognitions and the respective differentiation between perfectionistic strivings and perfectionistic concerns are relevant for a better understanding of how demands are related to psychological detachment and strain as proposed in the SD model. Investigating perfectionism as a vulnerability factor in employee samples and thereby integrating research on perfectionism in a well-established occupational health model should advance not only perfectionism research but also research on the SD model by including a promising relevant personal characteristic as a predictor of psychological detachment and strain and a moderator of effects of situational characteristics.

\section{2 | THE ROLE OF TRAIT PERFECTIONISM IN THE SD MODEL}

Despite considerable empirical support for the direct effects between demands, psychological detachment, and strain proposed by the SD model at the between-persons level (see Bennett, Bakker, \& Field, 2018; Wendsche \& Lohmann-Haislah, 2016, for reviews), the number of studies that have specifically examined the proposed mediating effects of psychological detachment is still limited (Sonnentag \& Fritz, 2015; Sonnentag, Kuttler, \& Fritz, 2010). Moreover, there is only limited knowledge about the role of personal characteristics for the relations between job stressors, psychological detachment, and strain. Integrating research on dispositional perfectionism in the SD model, we propose that not only might individual levels of DPC and DPS directly affect psychological detachment and strain, but they might also, more specifically, serve as moderators of the relations between specific job demands and psychological detachment as well as the relations between specific job demands and strain.

Individuals with higher DPC generally pay more attention to and feel concerned about the consequences of even minor discrepancies between an actual and a perfect goal status (e.g., Frost, Marten, Lahart, \& Rosenblate, 1990). On the one side, this negative focus will generally be associated with enhanced distress (see Stoeber \& Gaudreau, 2017, for a recent review; see, Dittner, Rimes, \& Thorpe, 2011; Lombardo, Mallia, Battagliese, Grano, \& Violani, 2013 for associations with specific strain responses, i.e., sleep quality and fatigue) as well as more frequent negative perseverative thinking about one's 
job (Flaxman et al., 2017; Flaxman, Ménard, Bond, \& Kinman, 2012) and thus a lack of psychological detachment from work during evening leisure time. This failure to detach again enhances perceived strain (see Sonnentag \& Fritz, 2015). On the other side, individuals with higher DPC are more likely to show a higher reactivity to specific job demands such as unfinished tasks or role ambiguity. "Unfinished tasks refer to tasks that the employee aimed to finish (or make certain progress), but which were left undone (or left in an unsatisfactory state) when the employee stopped working" (Syrek, Weigelt, Peifer, \& Antoni, 2017, p. 227). Unfinished tasks per se might trigger repetitive or intrusive thoughts about the incomplete task (Baumeister \& Bushman, 2010) and might remain highly accessible in memory (Masicampo \& Baumeister, 2011) even when employees leave the workplace. Thus, unfinished tasks might maintain feelings of tension or negative activation during off-job time and elicit work-related rumination (Syrek et al., 2017). This negative effect on recovery from work should be amplified in individuals with high levels of DPC. As individuals high in DPC are specifically concerned about the negative consequences of discrepancies between their actual and a perfect goal status, and unfinished tasks mean that a perfect goal status has not (yet) been reached, they should generally evaluate such job demands as more of a threatening hindrance in comparison with participants lower in DPC (cf. Zureck, Altstötter-Gleich, Gerstenberg, \& Schmitt, 2015).

A second job stressor that we suggest should be very relevant in the context of perfectionism is role ambiguity. Role ambiguity refers to "the extent to which one is confronted with unclear work situations" (Bowling et al., 2017, p. 3). Findings from between-persons studies regarding the associations between role ambiguity and psychological detachment have been inconsistent. Sonnentag and Fritz (2007) found a negative association between role ambiguity and psychological detachment, whereas other studies reported nonsignificant relations only (at least for self-reported role ambiguity; Sonnentag \& Kruel, 2006; Potok \& Littman-Ovadia, 2013). However, not having clear information about the nature of different tasks and the responsibilities and goals associated with them means that an employee can never be certain about whether a perfect goal status has actually been attained, and such uncertainty/ambiguity poses a specific threat for individuals high in DPC (Buhr \& Dugas, 2006; Kawamoto \& Furutani, 2018). In this vein, role ambiguity might result in increased general levels of strain and increased general levels of thinking about job-related issues-or in being involved in work-related tasks during nonwork time for employees who score high on DPC and who are especially concerned about not living up to their standards. Individuals with high DPS are also concerned about their high standards, but they tend to take a less negative view (e.g., Frost, Marten, Lahart, \& Rosenblate, 1990). They may also generally appraise demands such as unfinished tasks or role ambiguity as relevant but not necessarily as threatening hindrances (cf. Zureck et al., 2015). As such, participants with high DPS also frequently think about their job demands during evening leisure time but in a less negative way (e.g., Flaxman et al., 2017), and this kind of more positive thinking, in and of itself, might not be problematic (cf. Sonnentag \& Fritz, 2015).
Cross-sectional studies that have explored the association between dispositional perfectionism and perseverative thinking have consistently found that DPC are positively associated with a ruminative response style and that this response style mediates the associations between DPC and symptoms of depression and anxiety (e.g., Burns \& Fedewa, 2005; Di Schiena, Luminet, Philippot, \& DouiIliez, 2012; Flett, Madorsky, Hewitt, \& Heisel, 2002; Randles, Flett, Nash, McGregor, \& Hewitt, 2010). In addition, facets of DPC (but not DPS) have been associated with more frequent rumination about important mistakes and personal incompetence (e.g., Cox \& Chen, 2015; Frost et al., 1997). In a recent daily diary study, Flaxman et al. (2017) found that DPC positively predicted individual differences in work-related worry/rumination during evening leisure time and this in turn mediated the detrimental effects of DPC on sleep quality, emotional exhaustion, and work engagement reported the following day. By contrast, DPS showed positive indirect effects on work engagement mediated by positive thinking about work during evening leisure time. Whereas these studies did not take into account individual differences in perceived demands (e.g., job stressors) and did not directly assess psychological detachment (i.e., they assessed rumination), they indicate that DPS and DPC might differentially affect general levels of psychological detachment from work and strain. Following the reasoning outlined above, besides these main effects, the dimensions of dispositional perfectionism might moderate effects of general job stressors not only on individual differences in psychological detachment but also on individual differences in strain levels such as fatigue or sleep quality. Fatigue and sleep quality are two important albeit distinct indicators of perceived strain, they have both been investigated as criterion variables in the framework of the SD model in several studies (see Sonnentag \& Fritz, 2015), and they have also been associated with dispositional perfectionistic concerns (e.g., Dittner, Rimes, \& Thorpe, 2011; Lombardo, Mallia, Battagliese, Grano, \& Violani, 2013). Moreover, they have been shown to be important predictors of longterm psychological and physiological adjustment (see, e.g., Hockey, 2013; Groeger, Zijlstra, \& Dijk, 2004). In sum, on the between-persons level, our expectations regarding the overall SD model and the moderating effects of dispositional perfectionism in predicting individual differences in psychological detachment and strain can be summarized in the following hypotheses:

H1 Building on previous research on the SD model (Sonnentag \& Fritz, 2015), the effect of job demands on strain will be mediated psychological detachment.

H2 In individuals with high levels of DPC, the (a) negative relationship between job demands and psychological detachment and (b) positive relationship between job demands and strain will be stronger than for individuals with low levels of DPC.

H3 In individuals with high levels of DPS, (a) the negative association between job demands and psychological detachment will be stronger than for individuals with low levels of 
DPS, and (b) the positive association between job demands and strain will be comparable to the respective association for individuals with low levels of DPS.

\section{3 | THE ROLE OF PERFECTIONISTIC COGNITIONS IN THE SD MODEL}

Besides the effects proposed above at the between-persons level, we aim to investigate short-term dynamics that refer to the processes that unfold during a workday. The SD model suggests that not only will job stressors encountered during a workday lead to immediate strain reactions, but they will also result in more difficulties in detaching from work (Sonnentag \& Fritz, 2015). After a stressful workday, employees might more strongly recall or even ruminate about negative experiences or events, and they might anticipate or even worry that the next day might be stressful as well. As a consequence, they might feel less recovered, and their strain levels will remain elevated. At the within-person level of analysis, this short-term process might explain why daily job stressors such as daily unfinished tasks or role ambiguity not only directly affect daily strain but are also mediated by daily psychological detachment. In this vein, previous research has shown that such impairments of detachment can be found for different types of job stressors such as time pressure (Sonnentag \& Bayer, 2005) or illegitimate tasks (Sonnentag \& Lischetzke, 2018).

In their review, Sonnentag and Fritz (2015) proposed that based on transactional stress theory, the negative effects of job stressors on detachment should be moderated by, for example, "the attention a person directs to his or her job and associated stressors" (p. 93). The attention that an individual pays to job stressors should be strongly associated with the frequency of perfectionistic cognitions. Indeed, prior studies have reported positive associations between perfectionistic cognitions and perseverative thinking, indicated by a ruminative response style, the tendency to engage in perseverative thinking about failures, and the tendency to experience intrusive thoughts following stressful experiences (Flett, Hewitt, Blankstein, \& Gray, 1998; Flett, Madorsky, Hewitt, \& Heisel, 2002). In a more recent study, perfectionistic cognitions were found to be positively associated with the tendency to experience enhanced and prolonged reactivity to stressors (Flett et al., 2016). However, these studies were cross-sectional, investigated only student samples, did not differentiate between PSC and PCC, and did not take into account the effects of current stressors. Nonetheless, they indicate that perfectionistic cognitions might disturb psychological detachment from work and enhance work-related strain and more specifically intensify negative effects of specific relevant stressors on psychological detachment and strain.

A high prevalence of perfectionistic cognitions during a work day indicates that the "perfectionism mindset" (p. 97) has been activated by a relevant stressor (Flett, Hewitt, Nepon, \& Besser, 2018). If an employee frequently thinks about mistakes and the negative consequences of such mistakes (PCC) during a work day, this indicates that his or her perfectionistic concerns have been activated. As a consequence, the employee assigns a significant relevance to and thus focuses his or her attention on negative aspects of his or her own performance, and this focus enhances strain. In addition, he or she might still be inclined to engage in perseverative thinking about the importance, causes, and consequences of discrepancies between his or her actual and goal status during leisure time. This implies a further deterioration in the ability to detach during evening leisure time and thus maintained or even increased strain. Besides these main effects, PCC should enhance reactivity to specific relevant daily job stressors because these stressors will get more attention (cf. Sonnentag \& Fritz, 2015). This process most likely occurs when the job demands either keep the employee uncertain about the content of his or her tasks or relevant goals (i.e., role ambiguity), or the uncompleted task perpetuates attention and vigilance for opportunities to complete it (Masicampo \& Baumeister, 2011). Therefore, on days when an individual experiences more frequent PCC, both (a) negative associations between daily job stressors (e.g., unfinished tasks) or role ambiguity and daily psychological detachment and (b) positive associations between job stressors and daily strain should be enhanced.

By contrast, more frequent thoughts about one's standards (PSC) are less negative in valence, and thus, they should be less detrimental for work-related strain. PSC might be sustained in the form of perseverative thinking during leisure time, but this more positive mental engagement might be less detrimental (cf. Sonnentag \& Fritz, 2015). Our expectations of the within-person relations between daily job demands, daily psychological detachment, and daily strain and of moderating effects of perfectionistic cognitions in the SD model can be summarized in the following hypotheses:

H4 Building on previous research on the SD model (Sonnentag \& Fritz, 2015), the effect of daily job demands on daily strain will be mediated by daily psychological detachment.

H5 On days with more frequent PCC, the (a) negative association between daily job demands and daily psychological detachment and (b) positive association between daily job demands and daily strain will be stronger than on days with less frequent PCC.

H6 On days with more frequent PSC, (a) the negative association between daily job demands and daily psychological detachment will be stronger than on days with less frequent PSC, and (b) the positive association between daily job demands and daily strain will be comparable to the respective associations on days with less frequent PSC.

\section{2 | METHOD}

\section{1 | Participants and Procedure}

The study was conducted with employed volunteers who were recruited through local newspapers, flyers, and social media. We 
accepted individuals who worked at least part time but only those who were not involved in any kind of shift work. They were given an informed consent form along with additional information about the study. After providing informed consent, participants were invited to complete an online trait questionnaire. They were given additional information about the experience sampling assessments via smartphone and the study's procedure from a website.

The experience sampling part of the study took 3 work weeks. During this phase, participants were prompted each morning (Monday through Saturday), directly after work, and in the evenings (Monday through Friday). In the after-work sessions, job stressors and perfectionistic cognitions experienced during that work day as well as momentary strain were assessed. Each evening, participants rated their psychological detachment and momentary fatigue. In the morning, we assessed the strain indicators. The morning and evening sessions took approximately $3 \mathrm{~min}$ and the after-work sessions approximately $8 \mathrm{~min}$ each. Considering this high participant burden, to keep participants involved in the study, we used a bonus system that rewarded participation. Participants received $€ 30$ for completing at least $50 \%$ of the questionnaires during the 3 weeks of experience sampling. Alternatively, they were offered the opportunity to participate in a 3-week online introductory mindfulness training program. In addition, all participants were given the option to receive individual feedback that provided a summary of their responses in a written format. The study was approved by the local ethics committee.

Parallel to the publishing of the results, the data will be transferred in an anonymized form to the Open Science Framework Repository (https://osf.io/njhf3/) and will thereby be made available to the scientific community for further analyses.

\section{2 | Power Considerations}

Regarding the sample size needed to detect the mediation effect proposed in the SD model, Preacher, Zhang, and Zyphur (2011) showed that the power (i.e., rejection rate in a Monte Carlo simulation) to detect an indirect effect of .10 was $\geq .81$ for ICCs between .10 and .40 with $J \geq 100$ clusters with a within-cluster sample size of $n_{j}=20$. Because Hypotheses 1 through 3 refer to the upper levels of our hierarchical data (i.e., the person level), the sample size should allow us to estimate unbiased parameters for the mediation models at the person level as well. Li and Beretvas (2013) showed that a multilevel structural equation model required at least 80 clusters to circumvent convergence issues. To the best of our knowledge, no recommendations exist regarding power estimation for a moderated mediation within a multilevel structural equation model. Considering the requirements for the analyses mentioned above and assuming a drop-out rate of $30 \%$, our preregistration stated that we would recruit (stopping rule) 150 participants, resulting in $N_{\max }=2,250$ at Level 1 (if we considered the three measurement occasions required to estimate the full mediation model as one Level 1 unit). Due to dropout that occurred between study application and participation in the online trait questionnaire, we decided to recruit a few more participants. In the end, $N=160$ participants responded to the online trait questionnaire. Two participants withdrew their participation during the first few days of daily assessments. The final sample consisted of $N=158$ employees $\left(M_{\text {age }}=41.6 ; S D_{\text {age }}=10.9 ; 67 \%\right.$ women $)$ with an average contract of $36.8 \mathrm{hr}$ per week $(S D=6.4)$, an average number of years of professional experience of $17(S D=11.8)$, and an average of 9 years $(S D=9.0)$ with their current employer. The frequency of daily assessments per participant was 42 on average ( $\operatorname{Min}=6, n=1$; $\operatorname{Max}=48$, $n=24$ ), resulting in an overall number of assessments $N=2879$ at Level 1.

\section{3 | Measures}

\subsection{1 | Trait questionnaire}

On the trait questionnaire, participants were first asked to provide demographic information (i.e., sex, age, professional experience, and working hours per week). The two dimensions of dispositional perfectionism were assessed with two subscales from the Frost Multidimensional Perfectionism Scale (MPS-F; Frost, Marten, Lahart, \& Rosenblate, 1990; Altstötter-Gleich \& Bergemann, 2006). DPS was measured with the Personal Standards (e.g., "I have extremely high goals") subscale and DPC with the Concern over Mistakes (e.g., "If I fail partly, it is as bad as being a complete failure") subscale. Items are scored on a 6-point scale ranging from 1 (strongly disagree) to 6 (strongly agree). The two subscales are considered reliable and valid indicators of DPS and DPC (e.g., Frost, Heimberg, Holt, Mattia, \& Neubauer, 1993).

\subsection{2 | Experience sampling measures}

After work, daily job stressors were assessed in terms of unfinished tasks and role ambiguity. Building on previous work by Syrek and Antoni (2014) and Syrek et al. (2017), we measured unfinished tasks with three items (e.g., "I couldn't complete many of my tasks today, so now I need to finish them tomorrow" and "I am discontent that I didn't manage to complete today's important tasks"). The items were answered on a 5-point Likert scale ranging from 1 (strongly disagree) to 5 (strongly agree). Role ambiguity was measured with three items proposed by Bowling et al. (2017) and adapted to the daily time frame. Sample items are: "Today, I wasn't sure what was expected of me at work" and "Today, the requirements of my job were clear" (recoded). The items were answered on a 7-point scale ranging from 1 (strongly disagree) to 7 (strongly agree). The two facets of perfectionistic cognitions were assessed with six items that were suggested for the assessment of daily perfectionistic cognitions (Prestele, AltstötterGleich, \& Lischetzke, 2019). Originally, these items were adapted from existing trait measures of DPS and DPC to assess current thoughts that might occur during a day spent preparing for an examination. For the present study, we adapted the items to assess cognitions during the work day. A sample PSC item is "I want to perform particularly well at work." A sample PCC item is "Bother! I made a mistake here." Participants were asked to indicate how frequently each of the thoughts came to their mind during that work day ranging from 1 (not 
FIGURE 1 Hypothesized MSEM to test the person-level and day-level extensions of the SD model
Person-level model

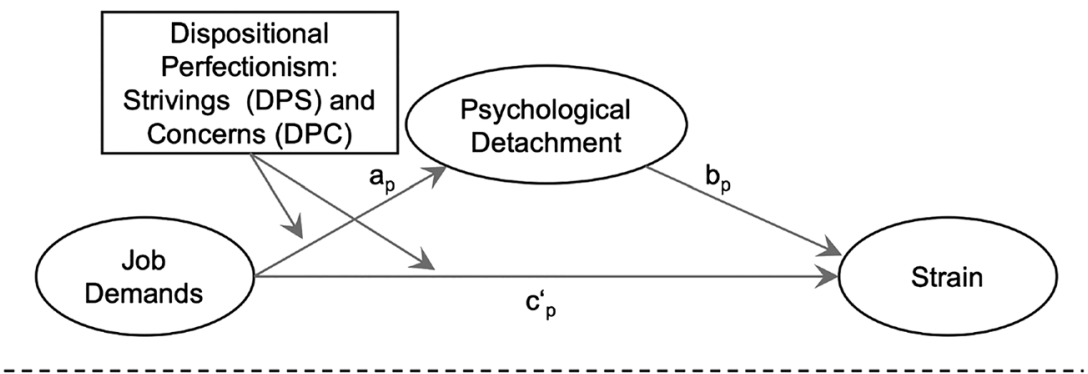

Day-level model

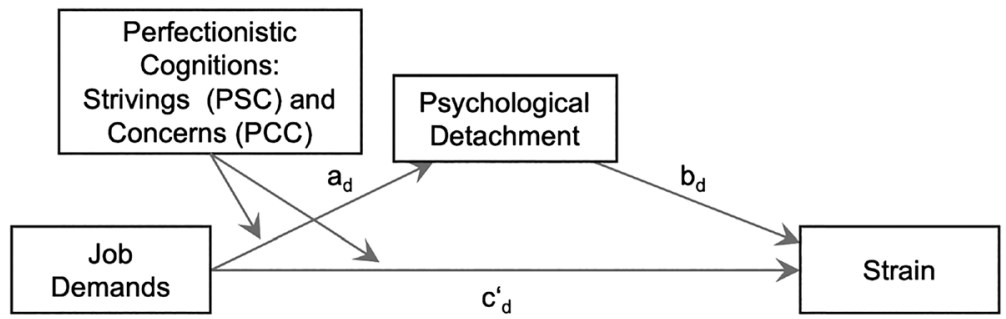

at all) to 6 (almost the entire time). Momentary strain was assessed as fatigue with four items from the Profiles of Mood Scales (fatigued, tired, exhausted, spent; McNair, Droppleman, \& Lorr, 1992). Responses were given on 5-point intensity scales ranging from 0 (not at all) to 4 (extremely).

In the evening, we assessed psychological detachment with the four-item measure developed by Sonnentag and Fritz (2007), adapted for day-specific assessment. Participants responded to items such as, "This evening, I forgot about work." The rating scale ranges from 1 (strongly disagree) to 5 (strongly agree). In addition, participants rated their momentary fatigue using the same items that were administered in the after-work session.

In the morning, strain was assessed as momentary fatigue using the same items as in the evenings and after work and as subjective sleep quality. Sleep quality was assessed with the sleep quality subscale from the Standardized Sleep Inventory (Görtelmeyer, 2011). Participants were asked to rate their last night's sleep with three adjectives (good, undisturbed, ample) ranging from 1 (strongly disagree) to 5 (strongly agree).

\section{4 | Data Handling and Statistical Analyses}

This paper is part of a larger project. An overview of all instruments used in the project is provided at the OSF: https://osf.io/njhf3/. Raw data and code will be uploaded parallel to manuscript publication under the same link. Data management and descriptive statistics were computed in R, whereas Mplus Version 8 was used to model the data. For this article, all available measurement occasions (but not all assessed constructs) were used in the analyses. We excluded participants from the analyses if they provided data on fewer than two measurement occasions. All remaining information was used in model estimation.

Some of our mediation and moderation hypotheses (Hypotheses 1 through 3b) represent hypotheses on the between-persons level, whereas others focus on processes within days (Hypotheses 4 through 6b). Hence, our data have a hierarchical structure with measurement occasions nested within individuals. As an analytical framework, we applied multilevel structural equation modeling (MSEM). MSEM can be applied to solve some of the limitations of conventional multilevel modeling techniques (see, e.g., Christ et al., 2017), and it can be used to test complex models. MSEM is a combination of multilevel modeling and structural equation modeling (Mehta \& Neale, 2005) and allowed us to estimate the proposed mediation and moderation effects at the within- and between-persons levels simultaneously. In addition, MSEM can accommodate unbalanced cluster sizes, missing data, and random slopes. For our analyses, in a first step, we computed multilevel confirmatory factor analyses (ML-CFAs) to test the accuracy of our measurements. In a second step, we estimated the full MSEM. Due to convergence issues (i.e., due to a high number of parameters in the complex conceptual model), we used the manifest scale scores of all constructs of interest. Overall, we computed four models: In Models 1 and 2, strain was operationalized as fatigue in the morning, and the level of fatigue assessed after work on the previous day was used as a covariate, whereas in Models 3 and 4, strain was operationalized as sleep quality. In Models 1 and 3, we computed the analyses with unfinished tasks as the predictor; in Models 2 and 4, role ambiguity was used as the predictor. The conceptual models and our hypotheses are presented schematically in Figure 1. Both predictors (i.e., unfinished tasks and role ambiguity), the mediator (i.e., psychological detachment), and both outcomes (i.e., fatigue and sleep quality) were measured daily. Following the recommendations recently made by Hayes and Rockwood (2018), we personcentered the predictors, whereas the within- and between-persons variances in the DVs were partitioned in Mplus and used to represent the constructs at the two levels of analysis. Perfectionistic cognitions were used as the moderator at the within-person level of analyses, whereas dispositional perfectionism was used as the between-persons moderator. Overall, as depicted in Figure 1, each 
model consisted of a person-level model (between-person level) and a day-level model (within-person level). Each person-level model concurrently investigated the effects of one predictor (i.e., unfinished tasks or role ambiguity), two moderators (i.e., DPS and DPC), the interactions of the moderators with the predictor, the mediator (i.e., psychological detachment), on one outcome (i.e., fatigue or sleep quality). In parallel, each day-level model concurrently investigated the effects of the predictor, two moderators (i.e., PSC and PCC), the interactions of the moderators with the predictor, the mediator, and the outcome. Besides direct main and interactive effects, we tested indirect effects of the predictors, the moderators, and the interaction terms on strain via psychological detachment in each model.

One common concern in the application of MSEMs is the question of how to obtain model convergence as well as admissible parameter estimates (Clifton \& Depaoli, 2018). One way to circumvent convergence problems in MSEMs is to use manifest scale scores (as mentioned above) or to fix the between-level residual variances to zero (see, e.g., Gottfredson, Panter, Daye, Allen, \& Wightman, 2009). In addition, we planned to compute the models with random slopes, but we also preregistered switching to models with random intercepts only if we needed to reduce model complexity. Nonetheless, inadmissible parameter estimates such as negative variances (Heywood cases) may still occur when using the Maximum Likelihood Estimator. Hence, for our analyses, we applied Bayesian estimation as implemented in Mplus (i.e., with noninformative priors). We determined the convergence diagnostic (Brooks \& Gelman, 1998), checked whether convergence remained after doubling the number of iterations, visually inspected the trace plots to ensure the stability of the Markov chains, and visually checked the smoothness of the histograms for all parameters.

In all models, we evaluated all parameter estimates for the associations in the models and report their $95 \%$ highest posterior density interval (HPD). Hypotheses 1, 2, 3a, 4, 5, and 6a would be supported if the HPD for the coefficient of the interaction term did not contain zero. Given that we proposed comparable effects in Hypotheses $3 b$ and $6 b$, they would be supported if the HPD for the coefficient of the interaction term contained zero. In addition, to be able to interpret the magnitudes of the effects, we report the standardized estimates provided by Mplus. Finally, for all models, the model fit was evaluated by means of posterior predictive checking (PPC). The hypotheses and analysis plan have been preregistered (https://osf.io/j2qc3).

\section{3 | RESULTS}

\section{1 | Preliminary Analyses}

The means, variances, reliabilities, intraclass correlations, and zeroorder correlations of the variables are shown in Table 1. The intraclass correlation (proportion of variance that is due to the person level) ranged from $29 \%$ (for sleep quality) to $73 \%$ (for PSC;

TAB LE 1 Bivariate correlations, higher-order means and variances, intraclass correlation coefficients, and reliability estimates of study measures at the within-person and between-persons level

\begin{tabular}{|c|c|c|c|c|c|c|c|c|c|c|c|c|c|}
\hline & & 1 & 2 & 3 & 4 & 5 & 6 & 7 & 8 & 9 & 10 & $\omega$ & $\rho$ \\
\hline \multicolumn{14}{|c|}{ Daily job stressors } \\
\hline 1 & Unfinished tasks & & .19 & - & - & .06 & .30 & -.14 & .21 & .05 & -.03 & .83 & .49 \\
\hline \multicolumn{14}{|c|}{ Dispositional perfectionism } \\
\hline 3 & Dispositional Perfectionistic Strivings & .11 & -.03 & & - & - & - & - & - & - & - & - & - \\
\hline \multicolumn{14}{|c|}{ Daily perfectionistic cognitions } \\
\hline 5 & Perfectionistic Strivings Cognitions & .22 & .11 & .41 & .47 & & .32 & -.02 & -.01 & .04 & -.05 & .73 & .73 \\
\hline 6 & Perfectionistic Concerns Cognitions & .55 & .61 & .10 & .49 & .35 & & -.17 & .21 & .05 & -.05 & .66 & .61 \\
\hline \multicolumn{14}{|c|}{ Psychological Detachment } \\
\hline 7 & Detachment & -.40 & -.24 & -.21 & -.23 & -.02 & -.31 & & -.13 & -.12 & .11 & .93 & .31 \\
\hline \multirow[t]{4}{*}{10} & Sleep quality (next morning) & -.28 & -.16 & -.10 & -.27 & -.01 & -.19 & .29 & -.54 & -.62 & & .81 & .29 \\
\hline & M & 2.45 & 2.53 & 4.40 & 3.35 & 3.54 & 2.22 & 3.47 & 2.87 & 2.64 & 3.40 & & \\
\hline & Var & 1.46 & 1.91 & 0.94 & 1.32 & 2.15 & 1.38 & 1.50 & 1.10 & 0.98 & 0.96 & & \\
\hline & $\omega$ & .97 & .90 & .86 & .91 & .95 & .92 & .98 & .95 & .94 & .85 & & \\
\hline
\end{tabular}

Note. Between-person ( $N=158)$ statistics below the diagonal, within-person $(N=2,879)$ statistics above the diagonal. 
see Table 1). Thus, all variables demonstrated substantial withinperson variability.

To show that the variables in the experience sampling part of the study were reliably measured, we conducted multilevel confirmatory factor analyses (MCFAs) with Mplus 8 (Muthén and Muthén, 1998-2017). The MCFAs showed an acceptable fit when they included the daily variables involved in the four analysis models, $\chi^{2}(d f)=2197.75(363)-1445.72(200)$, RMSEA $=.04-.05$, $\mathrm{CFI}=.89-.91, \mathrm{SRMR}$ (within) $=.03$, SRMR (between) $=.05-.06$. The detailed results (fit indices, standardized factor loadings, and latent correlations) can be retrieved from the OSF (Table A1). Finally, to estimate reliability at the within-person level, we applied the method proposed by Geldhof, Preacher, and Zyphur (2014). For the two between-persons constructs (DPS and DPC), we computed McDonald's omegas (see Table 1).

\subsection{Model and Hypotheses Testing}

Our four final models described above were computed as random intercept multilevel moderated mediation models using manifest scale scores. For all four models, visual inspection (trace plots and histograms) suggested stability and convergence of the models. We ran the models with 50,000 iterations and then doubled the number of iterations. For the four models, the convergence criterion PSR was $\leq 1.007$ in all post burn-in samples. With posterior predictive $p$-values (PPPvalues) of the models ranging from.465 (Model 1) to.472 (Model 3) and hence close to the "ideal" PPP-value of.50, all four models exhibited an excellent fit to the data.

Table 2 summarizes the unstandardized and standardized path coefficients of the direct and indirect paths estimated from our four analysis models ( 2 job demands $\times 2$ strain indicators). In our first hypothesis, we predicted that the mediation effect proposed in the SD model (i.e., the effect of job demands on strain will be mediated by psychological detachment) would replicate at the between-persons level of our analyses. In the four models, we found evidence for this postulated indirect effect only in Model 4 when job demands were operationalized as role ambiguity and strain was operationalized as sleep quality. In this model, role ambiguity reduced detachment, whereas detachment enhanced sleep quality. Whereas stressors were also identified as relevant predictors of detachment in Models 1 and 3, detachment was not a relevant predictor of strain in Models 1 to 3 , and the credibility intervals for the indirect effect included zero, suggesting no evidence for the mediation.

In Hypothesis 2, we predicted that at the between-persons level, perfectionistic concerns would moderate the negative relation between job demands and detachment and the positive relation between job demands and strain such that high levels of DPC would result in a stronger association between the aforementioned constructs. In all four models, we found no evidence for such interaction effects at the between-level. That is, DPC showed direct effects on strain only: It was negatively associated with sleep quality and positively associated with change in fatigue.
In our last hypothesis at the between-persons level of analysis, we predicted that for participants with high levels of perfectionistic strivings, the negative association between job demands and detachment would be stronger than for participants with low levels of DPS (H3a), but we expected no effect of DPS on the positive association between job demands and strain (H3b). In our data, we found no support for Hypothesis 3a. By contrast, Hypothesis H3b was supported in all four models because the effects were comparable insofar as they were null on average (i.e., credibility intervals included zero). Hence, at the between-level, DPS showed no effects on detachment and strain in the morning and no association with job demands.

In our first hypothesis referring to the within-level ( $\mathrm{H} 4)$, we aimed to replicate the basic mediation effect of the SD model. Indeed, in Models 1 and 3 (i.e., unfinished tasks as a job demand), we found that detachment mediated the effect of daily unfinished tasks on change in fatigue and on sleep quality the next morning. In these models, unfinished tasks reduced detachment, whereas detachment enhanced sleep quality and reduced fatigue. By contrast, in Models 2 and 4 (i.e., role ambiguity as a job demand), detachment was also a relevant predictor of sleep quality and fatigue. However, role ambiguity was not a unique predictor of strain, and we found no evidence of the mediation effects. Thus, Hypothesis 4 was only partially supported.

Further, we predicted that within-person fluctuations in daily perfectionistic cognitions would moderate associations between daily job demands and daily detachment. In Hypothesis 5, we predicted that on days with more frequently activated perfectionistic concerns, the negative association between daily job demands and daily detachment and the positive association between daily job demands and strain would be more attenuated than on days with less frequent PCC (H5). However, in all four models, we found no evidence of such moderating effects of PCC. However, PCC was negatively associated with detachment and thereby indirectly related to fatigue and sleep quality.

In our last hypothesis at the within-person level of analysis, we predicted that on days with more frequently activated perfectionistic strivings, the negative association between daily job demands and daily psychological detachment would be stronger than on days with less frequent PSC $(\mathrm{H6a})$, but we expected comparable positive associations between daily job demands and daily strain irrespective of the frequency of daily PSC (H6b). In our data, we found no evidence supporting Hypothesis 6a. Surprisingly, we found that on days with more frequent PSC, the association between role ambiguity and detachment was less negative (Models 2 and 3). Corresponding to Hypothesis 6b, PSC did not moderate the relation between job demands and strain in Models 1, 2, and 4 (i.e., the credibility intervals included zero). However, in Model 3, we found that on days with more frequent PSC, the negative effect of unfinished tasks on sleep quality was less strong than on days with less frequent PSC.

\section{4 | DISCUSSION}

The objective of our registered report was to conduct an experience sampling study to investigate the role of dispositional 


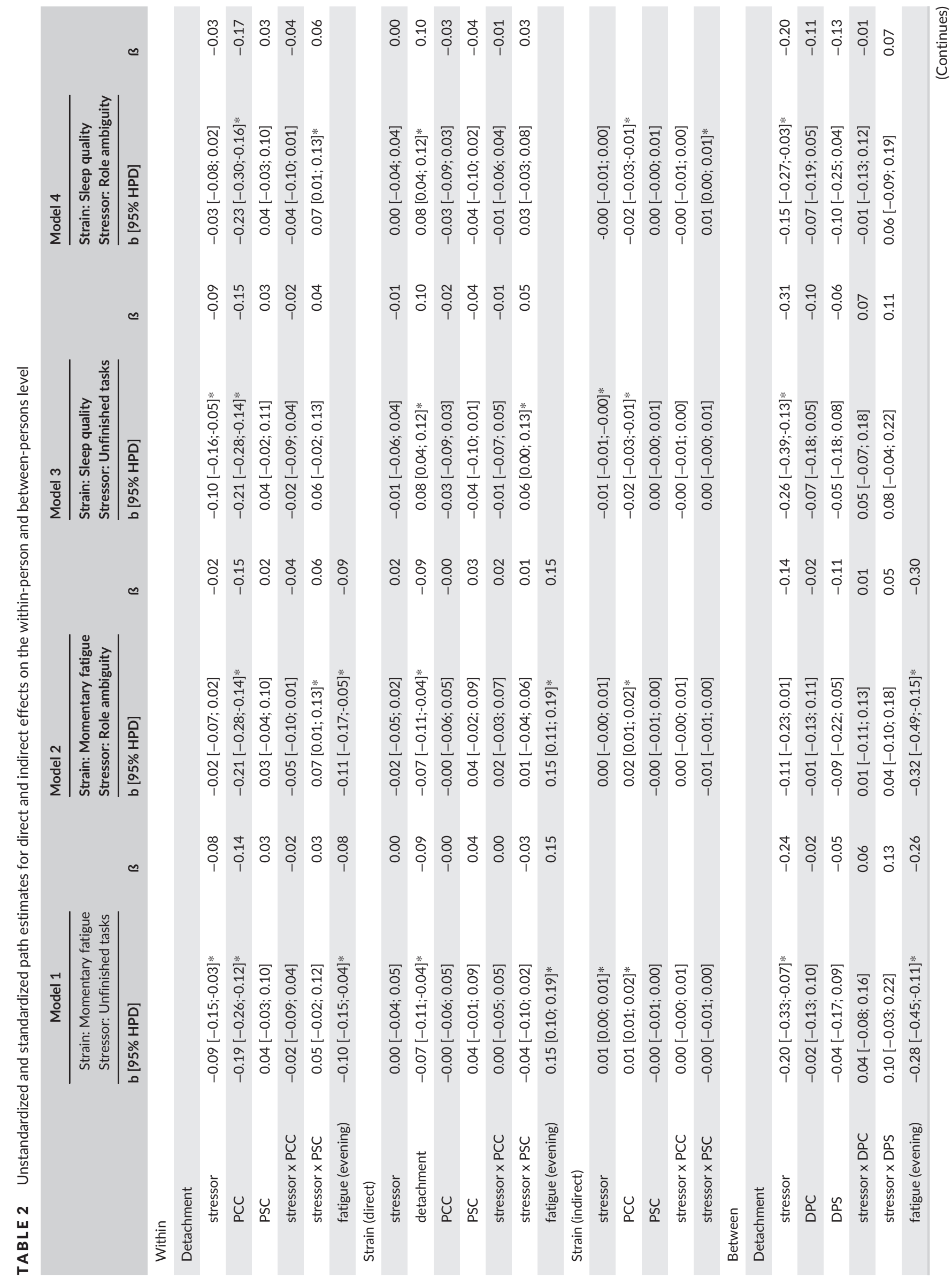




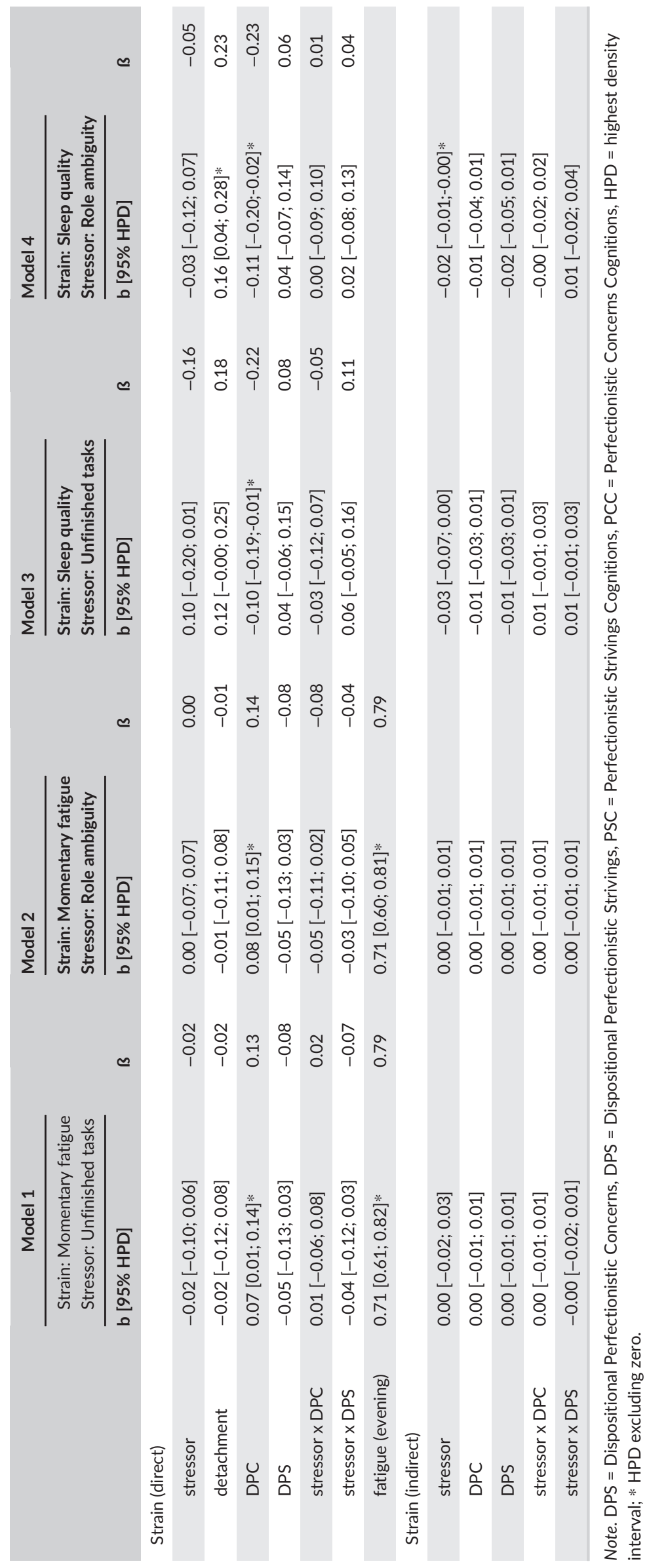


perfectionism and perfectionistic cognitions in the stressordetachment framework. On the between-persons level, we tested whether critical evaluations of a person's own behavior and concerns about the consequences of not living up to one's standards (DPC) and the setting of and striving for extremely high standards (DPS) would moderate the effects of job demands on psychological detachment and on job-related strain. In parallel, on the withinperson level, we examined whether a high prevalence of perfectionistic cognitions (i.e., a "perfectionism mindset") during work time would moderate the effects of daily job demands on the ability to detach from work and on daily strain levels such as feelings of fatigue and impaired sleep. Taken together, the support for our hypotheses was mixed.

\subsection{The Mediating Process in the SD Model}

One of the core assumptions in research on recovery is that recovery experiences such as psychological detachment mediate the association between job stressors and strain. Surprisingly, only a few primary studies have directly tested such effects of psychological detachment (see Sonnentag \& Fritz, 2015; Wendsche \& Lohmann-Haislah, 2017). In cross-sectional studies, detachment has been found to mediate the effect of job demands on fatigue (Kinnunen et al., 2010), exhaustion (Sonnentag et al., 2010), and perceived stress (Safstrom \& Hartig, 2013). One daily-diary study reported that detachment mediated the relation between work activities in the evening and vigor the following morning (ten Brummelhuis \& Bakker, 2012), and a meta-analytic review found support for an indirect effect from job demands to fatigue through psychological detachment (Wendsche \& LohmannHaislah, 2017). Given this primary and meta-analytical evidence, our mixed findings were rather unexpected. In our study, at the betweenlevel, we found support for the mediation effect in one out of four models (i.e., when looking at role ambiguity as the job demand and sleep quality as an indicator of strain). At the within-level, we found support for the mediation effect in the two models that included unfinished tasks as predictors of detachment, but not for role ambiguity. Also, our estimates of the indirect effects were considerably smaller than the meta-analytical estimate. At least two points should be considered when discussing these results. First, previous primary and secondary results did not necessarily apply to all possible combinations of job stressors and strain indicators. However, our choice of the specific constructs-albeit not atypical in occupational health research-was based on theoretical assumptions derived from perfectionism research. Consequently, we argue that the focus on more specific predictions contributes to a strengthening of the theory and clarifies its boundaries. Second, we planned our design to allow for a separation of predictors, mediator, and strain indicators in time. In doing so, we aimed to both improve our understanding of the underlying process and to reduce shared (method) variance in our assessments. However, the extent to which concurrent measurements blur actual effects is an open question: A recent meta-analysis (Pindek, Arvan, \& Spector, 2018) suggested that the associations between job stressors and strain tended to be weaker when predictors and outcomes were assessed concurrently in comparison with studies in which strain indicators were measured later in time than job stressors (i.e., when the supposed processes had time to unfold). Put differently, the time lag between the assessments might be a crucial (and overlooked) determinant of the divergent estimates across studies (see Kuiper \& Ryan, 2019).

With regard to the direct effects, at the within-person level, only unfinished tasks but not role ambiguity reported after work predicted psychological detachment during evening leisure time. Conceivably, the adverse effects of role ambiguity might result in stronger negative affective states during work time or directly after work but might be less salient before bedtime. By contrast, in accordance with the Zeigarnik effect, unfinished tasks might trigger work-related rumination (Berset, Elfering, Lüthy, Lüthi, \& Semmer, 2011; Syrek \& Antoni, 2014) and hence maintain a state of high negative activation or tense arousal and irritation-consequently impairing recovery processes. This finding contributes to the recently suggested concept of the "recovery paradox" (Sonnentag, 2018). In this paper, Sonnentag explained that, in general, recovery processes are often impaired when job stressors are high-although employees facing high levels of job stressors should prioritize their recovery in order to maintain well-being. However, it seems that findings regarding the association between specific job stressors and detachment stemming from diary studies differ from crosssectional findings (Sonnentag, 2018). In diary research and consistent with our findings, some stressors predict psychological detachment (e.g., self-control demands; Germeys \& De Gieter, 2018), whereas some stressors do not-or at least not linearly (e.g., time pressure; Haun, Nübold, \& Bauer, 2018).

With respect to direct effects of psychological detachment on strain, consistent with the literature, in our models, psychological detachment assessed before sleep predicted fatigue and sleep quality in the morning. In two meta-analyses (Bennet et al., 2018; Wendsche \& Lohmann-Haislah, 2017), the observed correlations between detachment and indicators of impaired well-being such as fatigue or exhaustion ranged from|.23|to|.42|. In our study, zero-order correlations at the within-person level of analysis were.29 for sleep and - .34 for fatigue. Not surprisingly, the effect sizes for the unique effects of detachment on strain after the effects of job stressors and perfectionism on strain were accounted for were smaller than the zero-order correlations reported in the meta-analytical reviews, and these estimates were relevant for the mediation effects postulated in the overall models. Still, we were able to detect the relation between psychological detachment and strain despite the facts that (a) the effect was examined "overnight" (i.e., we predicted fatigue and sleep quality in the morning from detachment assessed at bedtime) and (b) in two out of four models, we controlled for previous levels of fatigue. These results are consistent with several previous studies that reported significant effects of detachment (or the lack thereof) on negative states the next morning (Sonnentag, Binnewies, \& Mojza, 2008) and even after controlling for previous levels of these negative states (Sonnentag, 2008; Sonnentag \& Lischetzke, 2018). But, in a nutshell, we argue that the more or less consistent findings for the 
direct effects of job stressors on detachment and of detachment on strain cannot guarantee that mediation effects can be found with the same consistency. Also, because both individual differences in dispositional perfectionism and daily fluctuations in perfectionistic cognitions predicted daily strain, the associations between psychological detachment and strain found in our study were clearly smaller than the meta-analytical estimates of the bivariate associations.

\subsection{The Role of Perfectionism in the SD Model}

Beyond the basic mediation effect proposed in the SD model, an important goal of the present study was to extend research on recovery by investigating the role of dispositional perfectionism (betweenpersons level) and perfectionistic cognitions (within-person level) as personality variables that might be predictors and moderators of the stressor-detachment-strain associations across work days.

Concerning the predicted interaction effects, the only indication of the moderating role of perfectionism in the SD model was found on the within-person level and was contrary to our preregistered hypotheses: On days with more frequent PSC, the association between daily role ambiguity and daily detachment was less negative. Although we caution against overinterpreting this single and small effect, it might be explained against the background of research that has frequently revealed more positive associations of perfectionistic strivings with psychological adjustment, especially when the overlap with perfectionistic concerns was controlled for (e.g., Prestele \& Altstötter-Gleich, 2018; Stoeber \& Gaudreau, 2017; Stoeber, 2014). More specifically, such less detrimental effects of perfectionistic strivings compared to perfectionistic concerns were also reported for indicators of distress and detachment in the workplace (see Harari, Swider, Steed, \& Breidenthal, 2018 and Ocampo, Wang, Kiazad, Restubog, \& Ashkanasy, 2019 for recent reviews). Although we aimed to assess a lack of psychological detachment in a broader sense, that is, meaning both positive and negative engagement in work-related activities during evening leisure time, participants may have predominantly based their judgments on negative activities. Future studies might include questions for assessing what participants based their ratings of psychological detachment on in order to control for this potential imbalance or to specifically differentiate between rather negative problem-focused and more positive solution-focused activities that might help decrease strain during evening leisure time (cf. Ciarocco, Vohs, \& Baumeister, 2010). Beyond this single interaction effect, we did not find the expected moderating effects of perfectionistic concerns (DPC and PCC) on effects of job stressors on psychological detachment and strain responses or the expected moderating effects of perfectionistic strivings (DPS and PSC) on effects of job stressors on psychological detachment.

However, our analyses revealed negative main effects of perfectionistic concerns but not perfectionistic strivings on strain responses on both levels of analysis. This replicates prior findings that have consistently supported unique negative effects of linking DPC (see Hill et al., 2010; Stoeber \& Gaudreau, 2017, for overviews) and, in parallel, PCC (e.g., Prestele \& Altstötter-Gleich, 2018; Stoeber \& Gaudreau, 2017; Stoeber, 2014) with enhanced distress, whereas DPS and PSC have frequently been reported to be unrelated to distress, at least when the overlap with DPC or PCC was controlled for. On the between-persons level, DPC were consistently associated with enhanced fatigue and reduced sleep quality in the morning across all four models. On the within-person level, all direct effects of the two dimensions of perfectionistic cognitions on strain were not different from null effects. However, PCC but not PSC were associated with enhanced strain responses indirectly via psychological detachment. Such indirect effects of perfectionistic concerns on distress have previously reported dispositional perfectionism (DPC) via indicators of negative forms of cognitive perseverative activities (e.g., Cox \& Chen, 2015; Flaxman et al., 2017; Frost et al., 1997) but have not been investigated on the level of current perfectionistic thoughts, so far. This means that on days when participants experienced more frequent thoughts about mistakes and the negative consequences of such mistakes during work, they also reported a lack of detachment during evening leisure time irrespective of the number of relevant job stressors experienced that day (i.e., no moderation effect). This result extended prior evidence on effects of DPC on average levels of work-related worry and rumination (Flaxman et al., 2017, 2012) and on associations between perfectionistic cognitions and negative forms of perseverative thinking (not differentiating between PSC and PCC; Flett, Hewitt, Blankstein, \& Gray, 1998; Flett, Madorsky, Hewitt, \& Heisel, 2002) to specifically investigating fluctuations in perfectionistic concerns in the form of current thoughts on the within-person level. In contrast to our expectations and to evidence on the role of trait perfectionism in the workplace (see Harari et al., 2018 and Ocampo et al., 2019 for recent reviews), that consistently reported detrimental effects of perfectionistic concerns not only on indicators of strain and organizational behavior but also on motivational variables and detachment, we found no evidence that associations between the two dimensions of dispositional perfectionism and psychological detachment were different from zero at the between-persons level. This was surprising given Flaxman and colleagues' (Flaxman et al., 2017, 2012) results because they found that DPC and DPS were associated with unique forms of cognitive work-related behavior during evening leisure time (i.e., DPC with work-related worry/rumination but not positive thinking about work and DPS with positive thinking about work but not work-related worry/rumination). Both forms should mean that one is not "refraining from job-related activities and mentally disengaging from work during time off the job" (i.e., detachment; Sonnentag \& Fritz, 2015, p. 72). One important difference between the present study and the studies reported by Flaxman and colleagues was that in our final models, we controlled for average levels of daily job stressors. Regarding the bivariate associations between dispositional perfectionism and psychological detachment, we found evidence that DPS and DPC were negatively associated with psychological detachment, but this effect did not hold when the two dimensions of dispositional perfectionism were included as predictors of detachment 
along with relevant job stressors and evening levels of fatigue in one model. Thus, it might be the case that although DPS and DPC are generally associated with impaired detachment during evening leisure time, this effect is due to overlap between dispositional perfectionism, job demands, and strain experienced immediately after work.

Overall, our results showed that the differentiation between perfectionistic strivings and perfectionistic concerns on the levels of both dispositional perfectionism and perfectionistic cognitions is relevant for a better understanding of daily psychological detachment and strain responses. Whereas perfectionistic concerns were associated with enhanced strain responses on the levels of both between-person differences in DPC (directly) and within-person fluctuations in PCC (indirectly via psychological detachment), perfectionistic strivings were mostly unrelated to detachment and strain as assessed in the present study. However, perfectionistic strivings might be a relevant predictor of other specific variables in daily working life (e.g., positive thinking about work, work engagement; e.g., Flaxman et al., 2017; Stoeber \& Damian, 2016) not included in the SD model.

\section{3 | Limitations and Recommendations for Future Studies}

One critical decision we had to make for our research design was about the operationalization of the stressor part (i.e., job demands) of the SD model. Whereas prior research on the perfectionismspecific diathesis-stress model predominantly investigated broader classes of achievement versus social stressors (e.g., Flett, Nepon, Hewitt, \& Fitzgerald, 2016), we decided to investigate two specific job demands (i.e., unfinished tasks and role ambiguity) that should be highly relevant in the context of perfectionism. However, the advantage of the localization of narrowly defined stressors (e.g., unfinished tasks) in contrast to assessing a large variety of stressors under a common label (e.g., achievement stressors) comes along with the risk of missing other stressors that might have been equally or even more relevant on a specific work day, in a specific work environment, or for a specific person. This might be one explanation for the fact that we predominantly found main effects of perfectionistic concerns (trait and state) but no interactions with the narrowly defined stressors under investigation. Future studies might assess a broader range of job demands or a combination of broader and theoretically deduced specific demands in order to obtain a more detailed picture of the specific job demands that might interact with certain personality characteristics to predict psychological detachment and strain responses.

It was beyond the scope of our study to assess fluctuations in both daily job stressors and daily strain indicators with objective measures. Although it is the subjective perception of stressors that has immediate psychological consequences rather than objective situational characteristics, diathesis-stress models propose that personality characteristics affect the interpretation of objective situational characteristics. This means that the interaction between job stressors and personality characteristics might take place before a participant interprets a situational characteristic as a job stressor. More specifically, as participants high in perfectionistic concerns should be hypersensitive to deviations from an ideal state, they should more frequently report that they did not finish a task (at least not to their satisfaction) or that they were not sure that they did what was expected (i.e., role ambiguity). In order to reveal this mechanism, future studies might choose other approaches to the job stressors that employees face during their work days (e.g., experimental manipulations or interventions, third-party reports), which come along with their own diagnostic advantages and disadvantages but might constitute a valuable supplement to self-reported job stressors. Moreover, in addition to reports from others about well-being (Fritz, Yankelevich, Zarubin, \& Barger, 2010) or detachment (Sonnentag et al., 2010), future studies might implement objective measures such as cardiovascular and endocrinological indicators as indicators of strain (see Dettmers, VahleHinz, Bamberg, Friedrich, \& Keller, 2016; Radstaak, Geurts, Brosschot, Cillessen, \& Kompier, 2011).

Although the present research used a strong design with three measurement occasions per day and up to 48 measurement points per person, another limitation of our study is that due to model complexity, we were able to estimate only average effects. From a methodological point of view, it would be worthwhile to look at the within-person and between-persons variability in the postulated relations as well as at possible third variables at either the individual or organizational level that might account for such variability.

\section{4 | Practical implications}

The results of our study support the notion that both trait and state perfectionistic concerns play an important role for selfreported levels of strain and detachment in employees. Given that perfectionism is often considered to be "rewarded" and "useful" (Basco, 2000) in organizations, occupational health researchers should promote more knowledge on the "dark side" of perfectionism - or at least the "failure-avoiding" aspect of the construct. Taking into account meta-analytical evidence regarding the detrimental effects of perfectionism (Harari, et al., 2018), it might be a fruitful endeavor for organizations to foster a culture of clear communication regarding performance expectations and higher tolerance for mistakes. At the individual level, employees high in perfectionism should carefully evaluate working hours and selfexpectations regarding work-related goals. Our findings showing that PCC might negatively impact detachment seem worrying, given that recovery is known to mitigate negative correlates of perfectionism such as anxiety or burnout (Harari, et al., 2018).

Our results underscore the importance of bearing in mind personal characteristics when aiming at a supportive and healthy climate in the organization. Individuals with high levels of PCC are at risk for not being able to detach from work, resulting in high levels of fatigue and low sleep quality. Organizations should pay special attention to identifying employees at risk. Trainings 
combining more common stress management interventions with strategies taken from evidence-based treatments of perfectionism (see e.g. Egan, Wade, Shafran, \& Antony, 2014) could benefit a broad range of employees.

\section{5 | Conclusion}

This study contributes to research on psychological detachment in the framework of the SD model by investigating the role of trait perfectionism and state perfectionistic cognitions in the relations between daily job stressors, detachment, and strain. We showed that individual differences in perfectionism are directly related to fatigue and sleep quality, whereas fluctuations in perfectionistic concerns cognitions are associated with daily detachment-possibly impairing recovery processes. Likewise, regarding the mediation process proposed in the SD model, both the null findings and the considerably smaller effect sizes call for future studies to make even more precise predictions.

\section{FUNDING}

This research was supported by a grant from the Research Fund, Saarland University.

\section{CONFLICT OF INTEREST STATEMENT}

Both authors state that they do not have any conflicts of interest.

\section{DATA ACCESSIBILITY STATEMENT}

The data presented in this manuscript are published on the Open Science Foundation website (https://osf.io/njhf3/).

\section{ACKNOWLEDGMENTS}

We would like to thank M.Sc. Matti Meyer and M.Sc. Alexander Hart for their assistance in study preparation and data collection.

\section{ORCID}

Dorota Reis (D) https://orcid.org/0000-0002-0027-9713

\section{REFERENCES}

Altstötter-Gleich, C., \& Bergemann, N. (2006). Testgüte einer deutschsprachigen Version der Mehrdimensionalen Perfektionismus Skala von Frost, Marten, Lahart und Rosenblate (MPS-F). Diagnostica, 52(3), 105-118. https://doi.org/10.1026/0012-1924.52.3.105

Basco, M. R. (2000). Never good enough: How to use perfectionism to your advantage without letting it ruin your life. New York, NY: Simon \& Schuster.

Baumeister, R. F., \& Bushman, B. (2010). Social Psycology and human nature. Belmont, CA: Wadsworth
Bennett, A. A., Bakker, A. B., \& Field, J. G. (2018). Recovery from workrelated effort: A meta-analysis. Journal of Organizational Behavior, 262-275. https://doi.org/10.1002/job.2217

Berset, M., Elfering, A., Lüthy, S., Lüthi, S., \& Semmer, N. K. (2011). Work stressors and impaired sleep: rumination as a mediator. Stress and Health, 27(2), e71-e82. https://doi.org/10.1002/smi.v27.2.

Besser, A., Flett, G. L., Hewitt, P. L., \& Guez, J. (2008). Perfectionism, and Cognitions, Affect, Self-esteem, and Physiological Reactions in a Performance Situation. Journal of Rational-Emotive \& Cognitive-Behavior Therapy, 26(3), 206-228. https://doi.org/10.1007/s10942-0070067-0

Bowling, N. A., Khazon, S., Alarcon, G. M., Blackmore, C. E., Bragg, C. B., Hoepf, M. R., . . Li, H. (2017). Building better measures of role ambiguity and role conflict: The validation of new role stressor scales. Work \& Stress, 31(1), 1-23. https://doi.org/10.1080/02678373.2017. 1292563

Brooks, S. P., \& Gelman, A. (1998). General methods for monitoring convergence of iterative simulations. Journal of Computational and Graphical Statistics, 7(4), 434-455.

Buhr, K., \& Dugas, M. J. (2006). Investigating the construct validity of intolerance of uncertainty and its unique relationship with worry. Journal of Anxiety Disorders, 20(2), 222-236. https://doi.org/10.1016/j.janxdis. 2004.12.004

Burns, L. R., \& Fedewa, B. A. (2005). Cognitive styles: links with perfectionistic thinking. Personality and Individual Differences, 38(1), 103-113. https://doi.org/10.1016/j.paid.2004.03.012

Chang, E. C., \& Rand, K. L. (2000). Perfectionism as a predictor of subsequent adjustment: Evidence for a specific diathesis-stress mechanism among college students. Journal of Counseling Psychology, 47(1), 129. https://doi.org/10.1037/0022-0167.47.1.129

Christ, O., Hewstone, M., Schmid, K., Green, E. G. T., Sarrasin, O., Gollwitzer, M., \& Wagner, U. (2017). Advanced multilevel modeling for a science of groups: A short primer on multilevel structural equation modeling. Group Dynamics: Theory, Research, and Practice, 21(3), 121-134. https://doi.org/10.1037/gdn0000065

Ciarocco, N. J., Vohs, K. D., \& Baumeister, R. F. (2010). Some good news about rumination: Task-focused thinking after failure facilitates performance improvement. Journal of Social and Clinical Psychology, 29(10), 1057-1073. https://doi.org/10.1521/jscp.2010.29.10.1057

Clifton, J. P., \& Depaoli, S. (2018). Implementing multilevel structural equation models through Bayesian and Frequentist estimation: Simulation and applications. Working Paper.

Cox, S. L., \& Chen, J. (2015). Perfectionism: A contributor to social anxiety and its cognitive processes. Australian Journal of Psychology, 67(4), 231-240. https://doi.org/10.1111/ajpy.12079

Demerouti, E., Bakker, A. B., Geurts, S. A. E., \& Taris, T. W. (2009). Daily recovery from work-related effort during non-work time. In S. Sonnentag, P. L. Perrewe, \& D. C. Ganster (Eds.), Current perspectives on job-stress recovery: Research in occupational stress and well-being (pp. 85-123). Bingley: Emerald Group Publishing.

Dettmers, J., Vahle-Hinz, T., Bamberg, E., Friedrich, N., \& Keller, M. (2016). Extended work availability and its relation with start-of-day mood and cortisol. Journal of Occupational Health Psychology, 21(1), 105-118. https://doi.org/10.1037/a0039602

Di Schiena, R., Luminet, O., Philippot, P., \& Douilliez, C. (2012). Adaptive and maladaptive perfectionism in depression: Preliminary evidence on the role of adaptive and maladaptive rumination. Personality and Individual Differences, 53(6), 774-778. https://doi.org/10.1016/j.paid. 2012.05.017

Dittner, A. J., Rimes, K., \& Thorpe, S. (2011). Negative perfectionism increases the risk of fatigue following a period of stress. Psychology and Health, 26(3), 253-268. https://doi.org/10.1080/08870440903225892

Egan, S., Wade, T., \& Shafran, R. (2012). The transdiagnostic process of perfectionism. Revista de psicopatología Y psicología clínica, 17(3), 
279-294. Retrieved from. https://espace.curtin.edu.au/bitstream/ handle/20.500.11937/6676/241947_241947.pdf?sequence=2

Egan, S. J., Wade, T. D., \& Shafran, R. (2011). Perfectionism as a transdiagnostic process: A clinical review. Clinical Psychology Review, 31(2), 203-212. https://doi.org/10.1016/j.cpr.2010.04.009

Egan, S. J., Wade, T. D., Shafran, R., \& Antony, M. M. (2014). Cognitivebehavioral treatment of perfectionism. New York, NY: Guilford Publications.

Flaxman, P. E., Ménard, J., Bond, F. W., \& Kinman, G. (2012). Academics' experiences of a respite from work: effects of self-critical perfectionism and perseverative cognition on postrespite well-being. Journal of Applied Psychology, 97(4), 854-865. https://doi.org/10.1037/ a0028055

Flaxman, P. E., Stride, C. B., Söderberg, M., Lloyd, J., Guenole, N., \& Bond, F. W. (2017). Relationships between two dimensions of employee perfectionism, postwork cognitive processing, and work day functioning. European Journal of Work and Organizational Psychology, 56-69. https://doi.org/10.1080/1359432X.2017.1391792

Flett, G. L., Hewitt, P. L., Blankstein, K. R., \& Gray, L. (1998). Psychological distress and the frequency of perfectionistic thinking. Journal of Personality and Social Psychology, 75(5), 1363-1381. https://doi.org/10. 1037/0022-3514.75.5.1363

Flett, G. L., Hewitt, P. L., Demerjian, A., Sturman, E. D., Sherry, S. B., \& Cheng, W. (2012). Perfectionistic automatic thoughts and psychological distress in adolescents: An analysis of the Perfectionism Cognitions Inventory. Journal of Rational-Emotive \& Cognitive-Behavior Therapy, 30(2), 91-104. https://doi.org/10.1007/s10942-011-0135-3

Flett, G. L., Hewitt, P. L., \& Dyck, D. G. (1989). Self-oriented perfectionism, neuroticism and anxiety. Personality and Individual Differences, 10(7), 731-735. https://doi.org/10.1016/0191-8869(89)90119-0

Flett, G. L., Hewitt, P. L., Nepon, T., \& Besser, A. (2018). Perfectionism Cognition Theory: The Cognitive Side of Perfectionism. In J. Stoeber (Ed.), The psychology of perfectionism (pp. 89-110). New York: Routledge. https://doi.org/10.4324/9781315536255-7

Flett, G. L., Hewitt, P. L., Whelan, T., \& Martin, T. R. (2007). The Perfectionism Cognitions Inventory: Psychometric Properties and Associations with Distress and Deficits in Cognitive Self-management. Journal of Rational-Emotive \& Cognitive-Behavior Therapy, 25(4), 255-277. https://doi.org/10.1007/s10942-007-0055-4

Flett, G. L., Madorsky, D., Hewitt, P. L., \& Heisel, M. J. (2002). Perfectionism cognitions, rumination. And Psychological Distress. Journal of Rational-Emotive and Cognitive-Behavior Therapy, 20(1), 33-47. https://doi.org/10.1023/A:1015128904007

Flett, G. L., Nepon, T., Hewitt, P. L., \& Fitzgerald, K. (2016). Perfectionism, components of stress reactivity. And Depressive Symptoms. Journal of Psychopathology and Behavioral Assessment, 38(4), 645-654. https:// doi.org/10.1007/s10942-011-0131-7

Flett, G. L., Newby, J., Hewitt, P. L., \& Persaud, C. (2011). Perfectionistic Automatic Thoughts, Trait Perfectionism, and Bulimic Automatic Thoughts in Young Women. Journal of Rational-Emotive \& CognitiveBehavior Therapy, 29(3), 192-206. https://doi.org/10.1007/s10942011-0135-3

Fritz, C., Yankelevich, M., Zarubin, A., \& Barger, P. (2010). Happy, healthy, and productive: the role of detachment from work during nonwork time. Journal of Applied Psychology, 95(5), 977-983. https://doi.org/ 10.1037/a0019462

Frost, R. O., Heimberg, R. G., Holt, C. S., Mattia, J. I., \& Neubauer, A. L. (1993). A comparison of two measures of perfectionism. Personality and Individual Differences, 14(1), 119-126. https://doi.org/10.1016/ 0191-8869(93)90181-2

Frost, R. O., Marten, P., Lahart, C., \& Rosenblate, R. (1990). The dimensions of perfectionism. Cognitive Therapy and Research, 14(5), 449-468. https://doi.org/10.1007/BF01172967
Frost, R. O., Trepanier, K. L., Brown, E. J., Heimberg, R. G., Juster, H. R., Makris, G. S., \& Leung, A. W. (1997). Self-monitoring of mistakes among subjects high and low in perfectionistic concern over mistakes. Cognitive Therapy and Research, 21(2), 209-222. https://doi.org/10. 1023/A:1021884713550

Geldhof, G. J., Preacher, K. J., \& Zyphur, M. J.. (2014). Reliability estimation in a multilevel confirmatory factor analysis framework. Psychological Methods, 19(1), 72-91. https://doi.org/10.1037/a0032138

Germeys, L., \& De Gieter, S. (2018). A diary study on the role of psychological detachment in the spillover of self-control demands to employees' ego depletion and the crossover to their partner. European Journal of Work and Organizational Psychology, 27(1), 140-152. https://doi.org/10.1080/1359432x.2017.1417259

Geurts, S. A. E., \& Sonnentag, S. (2006). Recovery as an explanatory mechanism in the relation between acute stress reactions and chronic health impairment. Scandinavian Journal of Work, Environment \& Health, 32, 482-492. https://doi.org/10.5271/sjweh.1053

Görtelmeyer, R. (2011). Schlaffragebogen a und B - Revidierte Fassung [standardized sleep inventory for the SF-A/R and SF-B/R-revised version]. Göttingen: Hogrefe.

Gottfredson, N. C., Panter, A. T., Daye, C. E., Allen, W. F., \& Wightman, L. F. (2009). The effects of educational diversity in a national sample of law students: Fitting multilevel latent variable models in data with categorical indicators. Multivariate Behavioral Research, 44(3), 305-331. https://doi.org/10.1080/00273170902949719

Groeger, J. A., Zijlstra, F. R., \& Dijk, D. J. (2004). Sleep quantity, sleep difficulties and their perceived consequences in a representative sample of some 2000 British adults. Journal of Sleep Research, 13(4), 359-371. https://doi.org/10.1111/j.1365-2869.2004.00418.x

Harari, D., Swider, B. W., Steed, L. B., \& Breidenthal, A. P. (2018). Is perfect good? A meta-analysis of perfectionism in the workplace. Journal of Applied Psychology, 103(10), 1121-1144. https://doi.org/10.1037/ apl0000324

Haun, V. C., Nübold, A., \& Bauer, A. G. (2018). Being mindful at work and at home: Buffering effects in the stressor-detachment model. Journal of Occupational and Organizational Psychology, 91(2), 385-410. https://doi.org/10.1111/joop.12200

Hewitt, P. L., \& Dyck, D. G. (1986). Perfectionism, stress, and vulnerability to depression. Cognitive Therapy and Research, 10(1), 137-142. https://doi.org/10.1007/BF01173389

Hill, R. W., Huelsman, T. J., \& Araujo, G. (2010). Perfectionistic concerns suppress associations between perfectionistic strivings and positive life outcomes. Personality and Individual Differences, 48(5), 584-589. https://doi.org/10.1016/j.paid.2009.12.011

Hockey, R. (2013). The psychology of fatigue: Work, effort and control. Cambridge University Press.

Kawamoto, T., \& Furutani, K. (2018). The mediating role of intolerance of uncertainty on the relationships between perfectionism dimensions and psychological adjustment/maladjustment among mothers. Personality and Individual Differences, 122, 62-67. https://doi.org/10.1016/j. paid.2017.10.008

Kobori, O., \& Tanno, Y. (2005). Self-Oriented Perfectionism and its Relationship to Positive and Negative Affect: The Mediation of Positive and Negative Perfectionism Cognitions. Cognitive Therapy and Research, 29(5), 555-567. https://doi.org/10.1007/s10608-005-2835-4

Kuiper, R. M., \& Ryan, O. (2019). Preprint. Meta-Analysis of Lagged Regression Models: A Continuous-Time Approach.. https://doi.org/10.31234/ osf.io/5etkx

Li, X., \& Beretvas, S. N. (2013). Sample Size Limits for Estimating Upper Level Mediation Models Using Multilevel SEM. Structural Equation Modeling: A Multidisciplinary Journal, 20, 241-264. https:// doi.org/10.1080/10705511.2013.769391

Lombardo, C., Mallia, L., Battagliese, G., Grano, C., \& Violani, C. (2013). Perfectionism mediates the relationship between insomnia and 
depressive symptoms. Sleep and Biological Rhythms, 11(2), 90-98. https://doi.org/10.1111/sbr.12009

Mandel, T., Dunkley, D. M., \& Moroz, M. (2015). Self-critical perfectionism and depressive and anxious symptoms over 4 years: The mediating role of daily stress reactivity. Journal of Counseling Psychology, 62(4), 703-717. https://doi.org/10.1037/cou0000101

Masicampo, E. J., \& Baumeister, R. F. (2011). Consider it done! Plan making can eliminate the cognitive effects of unfulfilled goals. Journal of Personality and Social Psychology, 101(4), 667-683. https://doi.org/10. 1037/a0024192

McNair, D. M., Droppleman, L. F., \& Lorr, M. (1992). Edits manual for the profile of mood states: POMS. Edits.

Mehta, P. D., \& Neale, M. C. (2005). People are variables too: multilevel structural equations modeling. Psychological Methods, 10, 259-284. https://doi.org/10.1037/1082-989X.10.3.259

Ocampo, A. C. G., Wang, L., Kiazad, K., Restubog, S. L. D., \& Ashkanasy, N. M. (2019). The relentness pursuit of perfectionism: A review of perfectionism in the workplace and an agenda for future research. Journal of Organizational Behavior, 1-25. https://doi.org/10. 1002/job. 2400

Pindek, S., Arvan, M. L., \& Spector, P. E. (2018). The stressor-strain relationship in diary studies: A meta-analysis of the within and between levels. Work \& Stress, 1-21. https://doi.org/10.1080/02678373.2018. 1445672

Potok, Y., \& Littman-Ovadia, H. (2013). Does Personality Regulate the Work Stressor-Psychological Detachment Relationship. Journal of Career Assessment, 22, 43-58. https://doi.org/10.1177/ 1069072713487853

Preacher, K. J., Zhang, Z., \& Zyphur, M. J. (2011). Alternative Methods for Assessing Mediation in Multilevel Data: The Advantages of Multilevel SEM. Structural Equation Modeling: A Multidisciplinary Journal, 18(2), 161-182. https://doi.org/10.1080/10705511.2011.557329

Prestele, E., \& Altstötter-Gleich, C. (2018). Perfectionistic Cognitions: Stability, Variability, and Changes Over Time. Journal of Personality Assessment, 1-13. https://doi.org/10.1080/00223891.2017.1418746

Prestele, E., Altstötter-Gleich, C., \& Lischetzke, T. (2019). Better not think about it? Working Paper: Effects of positive and negative perfectionistic cognitions at times of increased pressure to perform.

Radstaak, M., Geurts, S. A., Brosschot, J. F., Cillessen, A. H., \& Kompier, M. A. (2011). The role of affect and rumination in cardiovascular recovery from stress. International Journal of Psychophysiology, 81(3), 237-244. https://doi.org/10.1016/j.ijpsycho.2011.06.017

Randles, D., Flett, G. L., Nash, K. A., McGregor, I. D., \& Hewitt, P. L. (2010). Dimensions of perfectionism, behavioral inhibition, and rumination. Personality and Individual Differences, 49(2), 83-87. https://doi.org/10. 1016/j.paid.2010.03.002

Safstrom, M., \& Hartig, T. (2013). Psychological Detachment in the Relationship between Job Stressors and Strain. Behavioral Sciences, 3, 418-433. https://doi.org/10.3390/bs3030418

Sonnentag, S. (2011). Recovery from fatigue: The role of psychological detachment. In P. L. Ackermann (Ed.), Cognitive fatigue: The current status and future for research and application (pp. 253-272). Washington, DC: American Psychological Association. https://doi.org/10.1037/ 12343-012

Sonnentag, S. (2018). The recovery paradox: Portraying the complex interplay between job stressors, lack of recovery, and poor well-being. Research in Organizational Behavior, 38, 169-185. https://doi.org/10. 1016/j.riob.2018.11.002

Sonnentag, S., \& Bayer, U.-V. (2005). Switching off mentally: predictors and consequences of psychological detachment from work during offjob time. Journal of Occupational Health Psychology, 10, 393-414. https://doi.org/10.1037/1076-8998.10.4.393
Sonnentag, S., Binnewies, C., \& Mojza, E. J. (2008). "Did you have a nice evening?" A day-level study on recovery experiences, sleep, and affect. Journal of Applied Psychology, 93, 674-684. https://doi.org/10.1037/ 0021-9010.93.3.674

Sonnentag, S., \& Fritz, C. (2007). The Recovery Experience Questionnaire: development and validation of a measure for assessing recuperation and unwinding from work. Journal of Occupational Health Psychology, 12(3), 204-221. https://doi.org/10.1037/1076-8998.12.3.204

Sonnentag, S., \& Fritz, C. (2015). Recovery from job stress: The stressordetachment model as an integrative framework. Journal of Organizational Behavior, 36, S72-S103. https://doi.org/10.1002/job.1924

Sonnentag, S., \& Kruel, U. (2006). Psychological detachment from work during off-job time: The role of job stressors, job involvement, and recovery-related self-efficacy. European Journal of Work and Organizational Psychology, 15(2), 197-217. https://doi.org/10.1080/ 13594320500513939

Sonnentag, S., Kuttler, I., \& Fritz, C. (2010). Job stressors, emotional exhaustion, and need for recovery: A multi-source study on the benefits of psychological detachment. Journal of Vocational Behavior, 76, 355-365. https://doi.org/10.1016/j.jvb.2009.06.005

Sonnentag, S., \& Lischetzke, T. (2018). Illegitimate tasks reach into afterwork hours: A multilevel study. Journal of Occupational Health Psychology, 23(2), 248-261. https://doi.org/10.1037/ocp0000077

Sonnentag, S., Venz, L., \& Casper, A. (2017). Advances in Recovery Research: What Have We Learned? What Should Be Done Next. Journal of Occupational Health Psychology.. https://doi.org/10.1037/ ocp0000079

Stoeber, J., \& Damian, L. E. (2016). Perfectionism in employees: Work engagement, workaholism, and burnout. In Perfectionism, health, and well-being (pp. 265-283). Springer. https://doi.org/10.1016/j.brat. 2017.05.015

Stoeber, J., \& Gaudreau, P. (2017). The advantages of partialling perfectionistic strivings and perfectionistic concerns: Critical issues and recommendations. Personality and Individual Differences, 104, 379-386. https://doi.org/10.1016/j.paid.2016.08.039

Stoeber, J., Kobori, O., \& Brown, A. (2014). Examining mutual suppression effects in the assessment of perfectionism cognitions: Evidence supporting multidimensional assessment. Assessment, 21(6), 647-660. https://doi.org/10.1177/1073191114534884

Stoeber, J., Kobori, O., \& Tanno, Y. (2010). The Multidimensional Perfectionism Cognitions Inventory-English ( $\mathrm{MPCl}-\mathrm{E})$ : Reliability, Validity, and Relationships With Positive and Negative Affect. Journal of Personality Assessment, 92(1), 16-25. https://doi.org/10.1080/ 00223890903379159

Syrek, C. J., \& Antoni, C. H. (2014). Unfinished tasks foster rumination and impair sleeping - particularly if leaders have high performance expectations. Journal of Occupational Health Psychology, 19(4), 490-499. https://doi.org/10.1037/a0037127

Syrek, C. J., Weigelt, O., Peifer, C., \& Antoni, C. H. (2017). Zeigarnik's sleepless nights: How unfinished tasks at the end of the week impair employee sleep on the weekend through rumination. Journal of Occupational Health Psychology, 22(2), 225-238. https://doi.org/10.1037/ ocp0000031

Wendsche, J., \& Lohmann-Haislah, A. (2016). A Meta-Analysis on Antecedents and Outcomes of Detachment from Work. Frontiers in Psychology, 7, 2072. https://doi.org/10.3389/fpsyg.2016.02072

Wendsche, J., \& Lohmann-Haislah, A. (2017). Detachment als Bindeglied zwischen psychischen Arbeitsanforderungen und ermüdungsrelevanten psychischen Beanspruchungsfolgen: Eine Metaanalyse. Zeitschrift für Arbeitswissenschaft, 71(1), 52-70. https://doi. org/10.1007/s41449-017-0044-0

Wirtz, P. H., Elsenbruch, S., Emini, L., Rüdisüli, K., Groessbauer, S., \& Ehlert, U. (2007). Perfectionism and the cortisol response to 
psychosocial stress in men. Psychosomatic Medicine, 69(3), 249-255. https://doi.org/10.1097/PSY.0b013e318042589e

Zureck, E., Altstötter-Gleich, C., Gerstenberg, F. X. R., \& Schmitt, M. (2015). Perfectionism in the Transactional Stress Model. Personality and Individual Differences, 83, 18-23. https://doi.org/10.1016/j.paid. 2015.03.029

\section{SUPPORTING INFORMATION}

Additional supporting information may be found online in the Supporting Information section at the end of this article.
How to cite this article: Reis D, Prestele E. The Role of Trait and State Perfectionism in Psychological Detachment From Daily Job Demands. Stress and Health. 2020;36:228-245. https://doi.org/10.1002/smi.2901 